\title{
OCULAR SYMPATHETIC PALSY IN PERIODIC MIGRAINOUS NEURALGIA
}

\author{
BY \\ E. A. NIEMAN* and L. J. HURWITZ \\ From the National Hospital, Queen Square, London
}

Harris $(1921,1926)$ described the main features of periodic migrainous neuralgia, and the subject has been well reviewed recently by Symonds (1956), by Bickerstaff (1959), and by Friedman, Carton, and Horanio (1960). We have examined the clinical features of 50 patients seen at the National Hospital in the past 10 years, of whom 24 were referred in the past 18 months. The observations in this series fully confirm the description of previous authors of the natural history of the pain, its prognosis, and the response to treatment with ergotamine tartrate.

The occurrence of ocular sympathetic paralysis in migrainous neuralgia has been mentioned by several authors (Harris, 1926; Horton, Maclean, and Craig, 1939; Horton, 1956; Bickerstaff, 1959) but neither its frequency nor its significance has been emphasized. We have been impressed by the number of patients in this series who have shown evidence of an ocular sympathetic palsy, and we believe that the association provides additional evidence of the vascular aetiology of the condition.

\section{Material}

All the patients in this study were referred initially to the National Hospital, Queen Square, by their general practitioners for diagnosis.

Of the 50 patients included in this series, 47 have been seen and examined personally by us. The details of the remaining three patients have been obtained by letter from them and their general practitioners. In addition to a general medical and neurological examination, $x$-ray examinations of the skull, paranasal sinuses, and chest were obtained in all cases, and carotid arteriograms in six patients. The majority of the patients have continued to attend the hospital for treatment until their symptoms have abated and the effects of treatment have been observed. The follow-up period ranges from six months to 10 years. All the patients are still living, except one who

*Present address: Neurological Department, St. Mary's Hospital, London, W.2. died from chronic bronchitis. None has developed another neurological disorder.

\section{Clinical Features of Migrainous Neuralgia}

The clinical characteristics of the syndrome have been described by many. The pain is always unilateral in an attack (or in a bout of attacks) but may affect either side in different bouts of pain. The pain is severe, and may be described as 'intense', 'agonizing', or 'excruciating', it is continuous and more often steady than throbbing. It may be maximal at onset but more commonly increases in intensity, reaching a maximum in 15 to 30 minutes. Individual attacks last one to two hours and seldom longer than three hours; Symonds (1956) stated that the attacks of only three of 17 patients lasted longer than two hours, a low figure compared with the present series, in which 15 patients had pain of over two hours' duration. Of these, nine patients mentioned pain of two to three hours' duration, but the remainder (six) described longer periods, of two to six hours' duration, one of whom rarely suffered pain lasting all day.

The duration of the pain is often remarkably constant and may occur in a particular patient at a particular time of day or night with clockwork regularity, and frequently waking him from sleep in the early hours of the morning. This latter feature is reported so commonly as to be almost typical. Attacks of stereotyped pain occur daily for as many as five to six times a day for weeks or months and then a spontaneous remission of weeks, months, or years may be succeeded by a further bout of attacks. This periodicity led to the use of the term 'cluster headaches'.

The situation of maximal pain is usually in or above the eye (Table I).

The pain may radiate to the forehead, temple, cheek, and ear, rarely to the jaws or to the neck but never to the other side of the head or face. Pain did not radiate in 11 patients in this series. 
TABLE I

SITE OF MAXIMAL PAIN IN 50 PATIENTS

\begin{tabular}{c|c|c|c|c|c}
\hline Eye & Supraorbital & Cheek & Temple & Vertex & Nose \\
\hline 21 & 15 & 3 & 7 & 2 & 2 \\
\hline
\end{tabular}

Associated features which accompanied the pain in most patients included lachrymation, suffusion of the (often ipsilateral) eye, rhinorrhoea and nasal congestion (usually unilateral), and less commonly periorbital oedema and facial flushing.

Six patients mentioned that the ipsilateral superficial temporal artery was prominent, dilated and sometimes tender during an attack.

Provoking factors were regarded as important by a few patients. A warm atmosphere was mentioned by eight patients, the (often dramatic) effect of alcohol by seven patients, worry, overwork, or stress by seven patients, and there was a single mention each of sneezing, hot flushes, bright light, stooping, and 'after a holiday'. It was rare to elicit methods of producing relief: local pressure on the neck (four), local heat (two), local cold (two), and trilene inhalation (one).

In this series the age of onset varied from 13 to 69 years with a peak incidence between 26 and 35 years. The sex incidence of 35 males and 15 females shows a higher incidence of females than in other series. The number of patients with a family history of migraine is similar to other series. There was a family history of migrainous neuralgia in three patients (Table II).

\section{Treatment and Prevention of Attacks}

The value of ergotamine tartrate either orally or parenterally has been emphasized by Symonds (1956). He found that when the patient was awakened regularly in the early morning by pain, a nocturnal injection of ergotamine might ensure a night's sleep by preventing pain.

Although a control study has not been attempted here we have found that prophylactic administration of ergotamine (usually given as Caffergot, $1 \mathrm{mg}$., in suppository form) has been convenient and effective, whereas sedatives and analgesics have been of little value. Symonds (1956) discusses the longterm regular use of ergotamine preparations and points out the potential complications of this drug, especially in elderly people. It must be emphasized that whilst prophylactic ergotamine often prevented pain entirely it would not terminate a bout of attacks; if the drug was stopped the attacks often returned. It may be necessary to continue prophylactic treatment until a natural remission occurs.

\section{Oculosympathetic Paralysis}

Signs of an oculosympathetic paralysis (either ptosis, miosis, or both) have been noted in 11 patients. In 10 of these the changes were permanent and in the other case ptosis and miosis were observed by us only during an attack of pain. The clinical features of these patients are noted in Table III. In four patients in whom attacks of migrainous neuralgia were observed personally by us, the ocular signs were seen to become more marked. Eye drops, $5 \%$ cocaine, were instilled topically in six patients with miosis. In five the miotic pupil remained smaller by $2 \mathrm{~mm}$. or more than the pupil of the other eye and in the other patient by less than $1 \mathrm{~mm}$. In all six, $10 \%$ neosynephrine produced rapid and full dilatation of the pupil. These results are in accord 0 ance with a sympathetic paresis as the cause of the miosis. In the four patients seen during an attac sweating was not diminished on the ipsilateral side of the face nor was this phenomenon noted o5 reported in any other case. However, in one patien in whom miosis was observed during an attack o甲 pain there was accompanying ptosis. This further. suggests sympathetic paresis and not parasympas thetic overactivity as the basis of the small pupil. An absent corneal reflex was found on the same side as the miosis in one patient, a woman now aged 51, having severe attacks of pain in the right eye for seven years, in whom the absent corneal reflex was first noted four years ago. A right carotid arteriogram was normal. This patient is an example of what has been termed Raeder's syndrome which will be discussed in more detail later. Except in this patient other neurological signs have always been lacking. Carotid arteriography was normal in six patients.

It is notable that in those patients with oculosympathetic involvement the average age of onset of pain is $\mathbf{4 2}$ compared with $\mathbf{3 5}$ for the whole series.

TABLE II

AGE OF ONSET AND SEX

\begin{tabular}{|c|c|c|c|c|}
\hline & Symonds (1956) & Bickerstaff (1959) & Friedman et al. (1960) & $\begin{array}{c}\text { Nieman and Hurwitz } \\
\text { (Present Series) }\end{array}$ \\
\hline $\begin{array}{l}\text { Total cases } \\
\text { Sex } \\
\text { Age of onset } \\
\text { Family history of migraine }\end{array}$ & $\begin{array}{c}17 \\
82 \% \text { male } \\
14-43 \\
\text { Average } 26 \cdot 9 \\
35 \%\end{array}$ & $\begin{array}{c}30 \\
70 \% \text { male } \\
\text { Peak } \\
30-40 \\
\text { Many }\end{array}$ & $\begin{array}{c}83 \\
\text { Predominantly male } \\
30-50 \\
20 \%\end{array}$ & $\begin{array}{c}50 \\
57 \% \text { male } \\
13-69 \\
\text { Peak 26-35 } \\
22 \%\end{array}$ \\
\hline
\end{tabular}


TABLE III

CLINICAL FEATURES OF PATIENTS WITH OCULOSYMPATHETIC PARALYSIS

\begin{tabular}{|c|c|c|c|c|c|c|c|c|}
\hline $\begin{array}{l}\text { Case } \\
\text { No. }\end{array}$ & Ocular Signs & Sex & $\begin{array}{c}\text { Age } \\
\text { of } \\
\text { Onset }\end{array}$ & $\begin{array}{l}\text { Age when } \\
\text { Ocular Signs } \\
\text { Noted }\end{array}$ & $\begin{array}{l}\text { Maximum } \\
\text { Site of Pain }\end{array}$ & $\begin{array}{c}\text { Associated Signs } \\
\text { during Periodic Pain }\end{array}$ & Periodicity of Pain & $\begin{array}{l}\text { Carotid } \\
\text { Arteriogram }\end{array}$ \\
\hline 1 & Ptosis + miosis & $\mathbf{M}$ & 32 & 34 & R. eyeball & $\begin{array}{l}\text { Lachrymation, } \\
\text { periorbital oedema }\end{array}$ & $\begin{array}{l}\text { Daily attacks in bout, } \\
\text { three } \\
\text { years }\end{array}$ & \\
\hline 2 & Ptosis + miosis & $\mathbf{M}$ & 69 & 71 & R. frontal & - & $\begin{array}{l}\text { years } \\
\text { First bout daily for four } \\
\text { months, second bout } \\
\text { daily for six months }\end{array}$ & \\
\hline 3 & Ptosis + miosis & $\mathbf{M}$ & 56 & 60 & R. eyeball & $\begin{array}{l}\text { Lachrymation, } \\
\text { conjunctival suffusion } \\
\text { periorbital oedema }\end{array}$ & $\begin{array}{l}\text { Two bouts a year for } \\
\text { nine years, daily attacks }\end{array}$ & Normal \\
\hline 4 & Ptosis + miosis & $\mathbf{M}$ & 31 & 45 & L. supraorbital & Lachrymation & $\begin{array}{l}\text { Bouts every two years for } \\
14 \text { years, three attacks a } \\
\text { day for three weeks }\end{array}$ & \\
\hline 5 & $\begin{array}{c}\text { Ptosis }+ \text { miosis } \\
\text { (bilateral) }\end{array}$ & $\mathbf{M}$ & 33 & $\begin{array}{l}\text { R.48 } \\
\text { L.55 }\end{array}$ & Temple & Ipsilateral rhinorrhoea & $\begin{array}{l}\text { Four bouts in } 22 \text { years } \\
\text { (3R. and } 1 \mathrm{~L} \text {.), three to } \\
\text { four attacks daily for }\end{array}$ & Normal \\
\hline 6 & Ptosis + miosis & $\mathbf{M}$ & 42 & 42 & R. cheek & $\begin{array}{l}\text { Lachrymation, } \\
\text { conjunctival suffusion, } \\
\text { ipsilateral rhinorrhoea }\end{array}$ & $\begin{array}{l}\text { three months } \\
\text { Bouts every two years for } \\
12 \text { years, daily attacks } \\
\text { recently for one and a } \\
\text { relf years }\end{array}$ & \\
\hline 7 & Miosis & $\mathbf{F}$ & 44 & 47 & R. eyeball & $\begin{array}{l}\text { Absent corneal, } \\
\text { lachrymation, } \\
\text { conjunctival suffusion, } \\
\text { nasal obstruction, }\end{array}$ & $\begin{array}{l}\text { Daily attacks for two } \\
\text { weeks, (longest re- } \\
\text { mission: two months in } \\
\text { seven years) }\end{array}$ & Normal \\
\hline 8 & Miosis & $\mathbf{M}$ & 54 & 60 & R. eyeball & $\begin{array}{l}\text { Lachrymation, } \\
\text { conjunctival suffusion, } \\
\text { periorbital oedema, } \\
\text { insilateral oeminorrhea }\end{array}$ & $\begin{array}{l}\text { Bouts every two years } \\
\text { for nine years, daily } \\
\text { attacks for four months }\end{array}$ & \\
\hline 9 & Ptosis & $\mathbf{F}$ & 44 & 51 & R. inner canthus & $\begin{array}{l}\text { Lachrymation, } \\
\text { conjunctival suffusion, } \\
\text { ipsilateral rhinorrhoea }\end{array}$ & $\begin{array}{l}\text { Two to three bouts a year } \\
\text { for seven years, daily } \\
\text { attacks for three months }\end{array}$ & \\
\hline 10 & Ptosis & $\mathbf{M}$ & 35 & 48 & R. eyeball & $\begin{array}{l}\text { Lachrymation, } \\
\text { ipsilateral rhinorrhoea }\end{array}$ & $\begin{array}{l}\text { Daily attacks for six } \\
\text { months, one bout a year }\end{array}$ & Normal \\
\hline 11 & Ptosis & $\mathbf{F}$ & 40 & 51 & R. eyeball & Periorbital oedema & $\begin{array}{l}\text { Duration } 11 \text { years, attacks } \\
\text { every day for a month, } \\
\text { remissions of two months }\end{array}$ & Normal \\
\hline
\end{tabular}

The average age of onset of oculosympathetic paralysis in the 13 patients is 49 . In four patients the interval between the onset of migrainous neuralgia and the development of ptosis and/or miosis was over 10 years.

Of particular interest is Mr. H. G., aged 55. His symptoms began in 1938 at the age of 33 . He complained of lancinating pain in the right eye, radiating to the cheek and temple and waking him from sleep at 2 a.m. every morning for three months. There was then a complete remission until 1944 when he had a similar bout affecting the right eye and a further right-sided bout in 1953. His fourth and last bout, however, in 1960 was left-sided, maximal over the temple and radiating to the eye and cheek. Antrum washouts were performed in 1938, a submucous resection of the nose in 1944. A right carotid arteriogram in 1953 was normal. In 1953 he noticed that during each attack the right eyelid drooped markedly and the right pupil became pin-point. Since that time he has had a permanent right-sided ptosis though the right pupil is now of normal size. In the recent bout of pain in 1960, however, he noticed left-sided ptosis and miosis and the left pupil was found on examination (during an interval between attacks of pain) to be smaller than the right.

He produced at one interview the following summary of his personal observations during attacks from April 28, 1960, to June 7, 1960.
1 Mental activity or complete relaxation appear to precipitate an attack.

2 Some tension or tightness in the left temple approximately 10 to 15 minutes before severe pain occurs.

3 Very high frequency whistle in head when attack pending.

4 Sharp, stabbing pains in left temple spreading to scalp, eye, and cheek.

5 'Veins' in left temple distend and feel hard to touch.

6 Obstruction occurs in left nostril.

7 Left pupil contracts, left eyelid droops. Eyes bloodshot.

8 Scalding or searing sensation in left nostril in some instances.

9 Perspiration on left of head during an attack.

10 Slight flow of clear mucus from left nostril as pain passes.

11 Tender or sore feeling in scalp after attack.

12 Attack usually followed by indigestion.

The incidence of $22 \%$ of patients with an oculosympathetic paresis is unexpectedly high. This may in part be due to the fact that 'simple' cases of migrainous neuralgia, i.e., without signs, and responding well to treatment may not have been included in the hospital diagnostic index. 


\section{Discussion}

Many names have been given to this type of cyclical facial pain: periodic migrainous neuralgia, Harris's neuralgia, cluster headaches, erthromelalgia of the head, histamine cephalalgia, red migraine, ciliary neuralgia, and others. It probably also embraces a number of other ill-defined (but supposedly distinct) syndromes such as Vidian neuralgia, Charlin's syndrome, and some cases of paratrigeminal neuritis (Raeder's syndrome). It was given its first clear description by Harris (1926) and has been more recently described and discussed by Symonds (1956), by Bickerstaff (1959), and by Friedman et al. (1960).

It is generally accepted that whatever the basic cause of the disturbance may be, the mechanism of the pain is stimulation of pain-sensitive fibres by vascular dilatation. Analysis of the site and radiation of the pain in all our cases suggests that the dilatation takes place in the territory of the internal and external carotid arteries. The more readily observable manifestations of this vascular dilatation are obvious in the flushing, increased warmth, and pulsating superficial temporal vessels. This superficial component, which implicates the external carotid artery, may be contrasted with the deep, boring, ocular pain which suggests an internal carotid artery origin. It is well recognized that some patients obtain relief by digital compression of either the superficial temporal artery or of the common carotid artery in the neck. That vasodilatation is responsible for the pain is supported by Horton's (1952) demonstration that the pain can be reproduced by injection of histamine. He was also able to abolish the histamine-induced pain with a vasoconstrictor (epinephrine). The efficacy of ergotamine tartrate in aborting a clinical or induced attack is due to its vasoconstrictor action which may also be employed prophylactically.

A phenomenon which has been noted by a few writers, but which has not been emphasized and its significance neglected, is the occurrence (either as a transient or as a permanent accompaniment) of an ocular sympathetic paralysis. Harris (1926) describes the case of a man aged 47 who noticed miosis and ptosis in his first attacks. This was present when Harris examined him and remained permanent. He discusses the mechanism and causation of this involvement. He says that the site does not seem to be in the ciliary ganglion because one would have expected parasympathetic effects and ocular muscle involvement, which were not present.

Horton mentions in his papers in 1939 and 1956 that a Horner's syndrome is not uncommon in 'histamine cephalgia'. He does not give the number of cases in which this was observed. Friedman and
Merritt (1959) state that 'a few patients with various forms of migraine present during the headache other signs of central neural activity, such as miosis and nasal congestion soon after the headache. These features suggest an integrated parasympathetic discharge of which the vasodilator headache is only one, although the most prominent feature'. Our observations, however, indicate a sympathetic paralysis, rather than a parasympathetic stimulation.

More recently Kunkle and Anderson (1960) have reported their findings of transient and persistent oculosympathetic signs in this condition. Of their 90 patients, six showed as a transient phenomenon miosis alone, and one showed miosis and ptosis. Seven patients showed persisting signs (two with miosis alone and five with ptosis in addition). They postulate that the fault results in some way from repeated dilatations of the internal carotid artery, and the sympathetic involvement occurs close to the carotid siphon.

In this series ocular sympathetic involvement occurred in $22 \%$ of cases.

Our findings emphasize the benign nature of the associated ocular sympathetic palsy when it occurs. It may disappear or lessen between attacks. Ocular sympathetic changes are found usually in patient who are middle-aged (youngest 34 but majority ove 45) and have had repeated bouts of attacks.

The combination of periodic facial pain and $q$ Horner's syndrome was also described in a group of cases by Raeder (1924). He described five patients in one it was due to neoplasm in the middle cranias. fossa, in two to local trauma, and in two cases no cause was discovered. In four of these the trigeminal nerve was involved with appropriate anaesthesia and he designated the picture the paratrigeminal syndrome. His Case 4 , where no cause was found, was the only patient without involvement of the trigeminal nerve. He felt that the lesion in these cases must be at the base of the middle fossa damaging the ocular sympathetic fibres in the wall of the internal carotid artery.

Ford and Walsh (1958), in a paper entitled 'Raeder's Paratrigeminal Syndrome', are in agreement with Raeder that in these cases the lesion must be at the base of the middle fossa on the basis of their observations of a series of 25 cases in which 'only pain above the eye and the oculosympathetic phenomena' were present. We think the term Raeder's syndrome should be reserved for cases in which there is clear evidence of a local lesion causing signs of trigeminal nerve involvement in conjunction with ocular sympathetic palsy and pain in the trigeminal distribution. Raeder's syndrome (thus defined) can be due to a number of local causes, including trauma and neoplasm. 
It has been suggested by Wolff (1948) that in a migrainous attack the artery becomes dilated, and that when the dilatation is prolonged, oedematous thickening occurs in its wall. The ocular sympathetic nerve fibres lie in the sheath of the internal carotid artery and might therefore be compressed.

Ocular sympathetic palsy has also been described in internal carotid artery occlusion where there is no evidence of a brain-stem disturbance (O'Doherty and Green, 1958). The most likely explanation is oedema or ischaemia of the carotid artery as a result of the thrombotic occlusion. It seems reasonable to conclude that dilatation of the carotid artery may produce pain and transient involvement of the sympathetic pathways, as in our cases of migrainous neuralgia; repeated dilatation may occasionally produce a permanent sympathetic lesion.

In referring to ocular sympathetic paralysis we have been careful not to use the term Horner's syndrome, as this term implies in addition to ptosis and miosis, unilateral anhidrosis. Although the latter was looked for, it was never encountered in this series, nor have other authors mentioned it. The sudomotor fibres travel along the external carotid artery, but although dilatation of the external carotid artery accounts for many of the manifestations of migrainous neuralgia, the involvement of the ocular sympathetic pathways is likely to be in the intraosseous portion of the internal carotid artery because there they would be particularly liable to damage against the bony wall.

Periodic migrainous neuralgia is therefore a relatively benign condition and recognition of the clinical features will save the patients unnecessary investigations and operations. The finding that the fifth cranial nerve is involved, however, makes it probable that there is some structural lesion in the middle cranial fossa.

\section{Summary}

The clinical features of 50 cases of periodic migrainous neuralgia have been studied.

Ocular sympathetic paralysis or paresis was present in 11 patients $(22 \%)$ and the mechanism has been discussed.

The relation of periodic migrainous neuralgia to Raeder's syndrome has been discussed and it is suggested that the latter term should be reserved for cases in which there are signs of trigeminal nerve involvement in addition to ocular sympathetic palsy and pain in the trigeminal distribution.

We are grateful to the Medical Committee of the National Hospital, Queen Square, for permission to publish this paper and to the physicians who allowed us to study cases under their care. We would like especially to thank Sir Charles Symonds for helpful advice in the preparation of this paper.

\section{REFERENCES}

Bickerstaff, E. R. (1959). Lancet, 1, 1069

Ford, F. R., and Walsh, F. B. (1958). Bull. Johns Hopk. Hosp., 103,

296.
Friedman, A. P., Carton, C. A., and Horanio, A. (1960). A.M.A. Arch. Neurol. Psychiat., 2, 1. and Merritt, H. H. (1959). Headache, p. 15. F. A. Davies, Philadelphia.

Harris, W. (1921). Proc. roy. Soc. Med., 14, 4 (1926). Neuritis and Neuralgia. Oxford University Press, New York.

Horton, B. T. (1952). Lancet, 72, 92.

(1956) Proc. Mayo Clin 31, 325.

Maclean, A. R., and Craig, W. McK. (1939). Ibid, 14, 257.

Kunkle, E. C., and Anderson, W. B. (1960). Trans. Amer. neurol. Ass., 85, 75 .

O'Doherty, D. S., and Green, J. B. (1958). Neurology, 8, 842.

Raeder, J. G. (1924). Brain, 47, 149.

Symonds, C. P. (1956). Ibid, 79, 217.

Wolf, H. G. (1948). Headache and Other Head Pain. Oxford University Press, New York. 